\title{
Current Concepts in the Pathogenesis and Management of Vascular Lesions - A Brief Review
}

\author{
Snehanjan Sarangi ${ }^{1}$, Debanjali Mukherjee
}

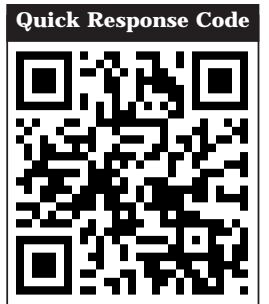

doi: $10.5866 / 2016.8 .10241$

${ }^{1}$ Dental Surgeon, Chanditala Rural Hospital,Hooghly,

West Bengal.

¿Senior Lecturer,

Department of Oral Pathology,

Ambedkar Institute of Dental Sciences \& Hospital, Bangalore, Karnataka.

\section{Article Info:}

Received: October 9, 2016

Review Completed: November 8, 2016

Accepted: December 10, 2016

Available Online: December, 2016 (www.nacd.in)

(C) NAD, 2016 - All rights reserved

\section{Email for correspondence:}

babi.sarangi@gmail.com

\begin{abstract}
:
Hemangiomas are considered to be benign tumors of infancy which show a rapid growth phase marked by endothelial cell proliferation, followed by gradual involution. On the other hand, vascular malformations are structural anomalies of blood vessels without endothelial cell proliferation. The pathophysiology of these lesions is still shroud in mystery. One etiol ogic hypothesis speculates that cells are "embol ized" from the placenta. Another suggests that hemangiomas result from somatic mutations in a gene mediating endothelial cell proliferation. Recent data suggest an endothelial progenitor cell as the source of origin of the tumors. It has been speculated that hypoxia, either systemically (e.g., due to placental insufficiency) or in a specific "niche" area of poorly perfused tissue stimulates endothelial progenitor cells to proliferate inappropriately. The fetal endothelial cell precursor cells, possess specific histochemical markers (GLUT-1, Lewis Y Antigen, merosin), similar to those on placental blood vessels. Abnormal levels of matrix metalloproteinases (MMP-9) and proangiogenic factors (VEGF, b-FGF, and TGF-beta 1) play a crucial role. Genetic errors in growth factor receptors have also been shown to affect development of hemangiomas. Recent discoveries concerning hemangioma pathogenesis provide both an improved understanding and more optimal approach to workup and management like corticosteroid or propranolol therapy. I mportant detrimental associations can be seen with hemangioma, such as significant structural anomalies. Standards of care have dramatically changed evaluation and management of hemangiomas. Herein, we have briefly discussed the factors that contribute to the formation of hemangiomas and vascular malformations in general along with their management.
\end{abstract}

Key words: Hemangioma, pathogenesis, treatment modalities.

\section{INTRODUCTION}

Vascular anomalies are congenital lesions of abnormal vascular development. Previously referred to as vascular birthmarks, vascular anomalies are now classified based on a system developed in 1982 by Mulliken and Glowacki that considers histology, biological behavior, and clinical presentation of these entities. ${ }^{1} \mathrm{~A}$ primary distinction is made between a vascular tumor, which grows by cellular hyperplasia, and a vascular malformation, which represents a localized defect in vascular morphogenesis. ${ }^{2}$ 
Both vascular tumors and malformations may occur anywhere on the body. In brief, hemangiomas are vascular tumors that are rarely apparent at birth, grow rapidly during the first 6 months of life, involute with time and do not necessarily infiltrate but can sometimes be destructive. Vascular malformations are irregular vascular networks defined by their particular blood vessel type. In contrast to hemangiomas, they are present at birth, slow growing, infiltrative, and destructive. ${ }^{3}$

Hemangiomas are categorized into two types: "infantile" or "congenital." The rare "congenital" hemangioma is less understood and present at birth. Congenital hemangiomas either rapidly involute (rapidly involuting congenital hemangioma ( $\mathrm{RICH})$ ) over a very brief period in infancy or never involutes (noninvoluting congenital hemangioma-NICH). ${ }^{3}$

The pathogenesis of hemangioma-one of the key and fascinating aspects; is still not properly understood. Although growth factors and hormonal and mechanical influences have been postulated to affect the abnormal proliferation of endothelial cells in hemangioma, the primary, causative defect in hemangiogenesis remains unknown and no genetic alteration has been implicated.The dearth of molecular details is striking, considering the growing list of germline mutations in genes causing specific inherited syndromes involving vascular malformations, including hereditary hemorrhagic telangiectasia ,cutaneous venous malformations, cerebral cavernous malformations, and hyperkeratotic cutaneous Capillary-venous mal formation. ${ }^{4}$

Although many of these lesions resolve spontaneously without concern, a significant proportion leads to function threatening and cosmetically disfiguring consequences. For functionally significant or potentially deforming lesions, timely intervention is important to minimize the possibility of a poor outcome and permanent scarring. Many important and management-altering discoveries have occurred regarding hemangiomas in the past decade. ${ }^{5}$

The goal of timely recognition and therapy is to minimize or el iminatelong-term sequelae.Standards of care have dramatically changed evaluation and management of hemangiomas. New modalities, such as oral propranolol, provide the caregiver with better therapeutic options, which can prevent or minimize medical risk or scarring. ${ }^{6} \mathrm{Here}$, we are presenting the various theories involving the pathogenesis of hemangiomas with a view to enrich its treatment and management modalities.

\section{OVERVIEW OF HEMANGIOMA}

Vascular tumors and malformations may occur anywhere on the body. In brief, hemangiomas are vascular tumors that are rarely apparent at birth, grow rapidly during the first 6 months of life, involute with time and do not necessarily infiltrate but can sometimes be destructive. Vascular malformations are irregular vascular networks defined by their particular blood vessel type. In contrast to hemangiomas, they are present at birth, slow growing, infiltrative, and destructive and persist throughout the life of the patient. Due to their complexity, a multidisciplinary approach is frequently necessary in managing these lesions and includes a team of specialists in pediatric otolaryngology, dermatology, hematology, interventional radiology, surgery, orthopedics, and sometimes psychology. ${ }^{7}$

\section{CLASSIFICATION OF VASCULAR} ANOMALIES

\begin{tabular}{|c|c|c|}
\hline Vascular tumors & \multicolumn{2}{|c|}{ Vascular malformations } \\
\hline & \multicolumn{2}{|c|}{ Slow-flow } \\
\hline Infantile hemangioma & \multicolumn{2}{|c|}{ Capillary malformations } \\
\hline Congenital hemangioma & \multicolumn{2}{|c|}{ Venous malformations } \\
\hline Tufted angioma & \multicolumn{2}{|r|}{ Lymphatic malformations } \\
\hline $\begin{array}{l}\text { Kaposiform } \\
\text { hemangioendothelioma }\end{array}$ & \multicolumn{2}{|c|}{ Fast-flow } \\
\hline & \multicolumn{2}{|r|}{ Arteriovenous malformations } \\
\hline \multicolumn{3}{|c|}{$\begin{array}{l}\text { OLD VERSUS CURRENT NOMENCLATURE } \\
\text { FOR DESCRIBING HEMANGIOMA TYPES: }\end{array}$} \\
\hline Old nomenclature & & New nomenclature \\
\hline Strawberry or capillary $h$ & & Superficial hemangioma \\
\hline Cavernous hemangioma & & Deep hemangioma \\
\hline Capillary cavernous hema & & Compound hemangioma \\
\hline
\end{tabular}

\section{PATHOPHYSIOLOGY}

The pathophysiology associated with the unique natural history of these lesions, with initial rapid proliferation followed by gradual involution and regression, has not been completely elucidated.

One theory suggests that hemangioma endothelial cells arise from disrupted placental tissue imbedded in fetal soft tissues during gestation or birth. Histochemical markers of hemangiomas, 
such as GLUT-1, Lewis $Y$ antigen, FcyRII, and merosin have been shown to coincide with those found in placental tissue. This is further supported by the fact that they are found more commonly in infants following chorionic vill us sampling, placenta previa, and preedampsia. ${ }^{8} \mathrm{~A}$ different theory arose from the discovery of endothelial progenitor and stem cells in the circulation of patients with hemangiomas. ${ }^{9}$ The development of hemangiomas in animals from stem cells isolated from human specimens supports this theory. However, infantile hemangiomas most likely arise from hematopoietic progenitor cells (from placenta or stem cell) in the appropriate milieu of genetic alterations and cytokines. ${ }^{10}$ Abnormal levels of matrix metalloproteinases (MMP-9) and proangiogenic factors (VEGF, b-FGF, and TGF-beta 1) play a role in hemangioma pathogenesis. Genetic errors in growth factor receptors have also been shown to affect development of hemangiomas. ${ }^{11}$ It has been speculated that hypoxia, either systemically (e.g., due to placental insufficiency) or in a specific "niche" area of poorly perfused tissue stimulates endothelial progenitor cells to proliferate inappropriately. ${ }^{12}$

IHs are vascular tumors that involve the proliferation of benign endothelial like cells that possess histochemical markers (GLUT-1, Lewis $Y$ antigen, FcyRII, and merosin); these markers are also present on placental blood vessels. ${ }^{13}$ The immunohistochemical profile differentiates infantile hemangiomas $(\mathrm{IH})$ from other vascular birthmarks or tumors. Hemangiomas display high levels of immunostaining for the GLUT1 glucose transporter, a surface protein that is highly expressed in most embryonic and fetal endothelial cells but is lost in most tissues except at the blood-tissue barriers, including micro vessels in the central nervous system and the placenta. ${ }^{14}$

\section{VARIOUS THEORIES REGRARDING PATHOGENESIS OF HEMANGIOMA}

The placental theory is attractive because it would explain the programmed life cycle of infantile hemangi oma $(\mathrm{IH})$. Subsequent to N orth's discoveries regarding the histochemical similarities of $\mathrm{IH}$ and placenta, Barnes et al noted that placenta and hemangioma have high levels of genetic similarity when compared with other vascular tumors and normal structures. ${ }^{4}$ Waner et al noted that IH tend to devel op al ong embryonic fusion lines of the facial placodes. ${ }^{15}$ Piecing these 2 seemingly disparate facts together, Mihm et al suggested that hemangioma might represent "benign metastases" originating from the placenta or other cells that proliferate in areas of low oxygen tension, such as the "end artery, vascular dead end" sites occurring in embryonic fusion planes. ${ }^{8}$ Pittman et al were unable to detect the presence of maternal-fetal chimerism in lesional tissue, but this does not rule out the possibility of the placental origin of hemangioma tissue because the placenta is predominantly fetal in origin. ${ }^{16}$ E mbolic placental endothelial cells could reach fetal tissues from chorionic villi through right-to-left shunts characteristic of the normal fetal circulation. The embolus might possess a single endothelial cell or only a small number of endothelial cells. ${ }^{17}$

It has also been hypothesized that immature endothelial cells and pericytes, which coexist in the late stages of fetal development, perhaps maintain persistent proliferative properties for a period of time postnatally, leading to the development of $\mathrm{IH} .{ }^{18}$ However, Boye et al demonstrated the clonality of $\mathrm{IH}$ cells, making it less likely that a disparate group of cells serve as the source of this tumor. ${ }^{17}$

Hypoxia has been proposed as a driving factor for the pathogenesis of vascular proliferation in general. Vascular proliferation may bea homeostatic attempt to normalize hypoxic tissue. E pidemiologic findings support this hypothesis, given that factors that are thought to be linked to hypoxia, such as low birth weight and advanced maternal age, are overrepresented in hemangioma populations. ${ }^{12}$ Another supportive finding is the association of $\mathrm{IH}$ with retinopathy of prematurity, a condition known to be linked to ischemia. ${ }^{19}$ GLUT-1, present on IH tissue, is a facilitative glucose transporter that is an important sensor for hypoxia. ${ }^{20}$

The growth of IH likely involves angiogenic peptides, such as vascular endothelial growth factor (VEGF) and basic fibroblast growth factor, which induce proliferation of blood vessels. Receptors for these growth factors are also crucial in endothelial cell regulation, and a misbalance of VEGF receptor- 1 expression with consequent hyperactivity of VE GF -receptor-2 function has been noted in IH tissue. ${ }^{21}$ The suppressive effect of glucocorticoids may be mediated through VEGF-A. Additionally, insulin like growth factor-2, which stimulates angiogenesis, is upregulated in proliferating but not involuting blood vessels. ${ }^{22}$ 
Endothelial progenitor cells (EPCs) are vascular stem cells with the capacity to contribute to postnatal vascular development. There is now compelling evidence that these EPCs play an etiologic role in the development of $\mathrm{IH}$. A subset of progenitor cells isolated from IH tissues, which possess the surface markers CD34+CD133+, are of particular interest. These EPCs have been shown to differentiate into endothelial cells in vitro22 and are increased 15- fold in I H compared with controls.7 Cultured EPCs from patients with IH stain positively for known hemangioma markers GLUT1, CD32, and merosin. ${ }^{23}$

Boye and colleagues show how the Cell autonomous defects in hemangioma take place- In an experiment, endothelial cells they isolated from hemangiomas exhibit enhanced proliferation and migration, in keeping with the rapid growth of the vascular lesion in the neonate. However, there was one surprise: In the presence of the angiogenic inhibitor endostatin, migration of these cells was not inhibited but rather stimulated, suggesting a radically altered cellular phenotype. One possible explanation, favored by the authors, is that a precursor endothelial cell had undergone a mutation in a gene regulating angiogenesis, resulting in clonal expansion. ${ }^{17}$

Several mediators of EPC trafficking and vasculogenesis, such as VEGF-A and hypoxia inducible factor-1 al pha (a transcription factor that regulates the formation of new blood vessels by EPCS), were found to be elevated in blood and IH specimens taken from children with proliferating $\mathrm{IH} .{ }^{24}$

A major breakthrough occurred when Khan et al were able to successfully inject CD133+E PCs from human hemangioma tissue into immunodeficient mice. These mice then developed GLUT1 vascular tumors, which recapitulated the development of human $\mathrm{IH}$, providing investigators with the first viablelH animal model. Thesestudies highlight the importance of CD133+EPCs in the pathophysiology of $\mathrm{IH}$ and providea means of testing putative therapies in this animal model..$^{25}$

The pathogenesis of Arterio venous hemangiomas originates with fetal endothelial cell precursors. During development, one or few of these cells lose their ability to produce or secrete platelet derived growth factor (PDGF) and transforming growth factor beta 1 (TGF â1), (Marx) which are required to recruit adventitial cells around developing vessels. Consequently, the daughter cells and eventually the vessels that arise from these original cells develop as single cell lined vessels (arteriole, venule, vein etc). During prepuberty there is usually insufficient pressure to cause these structurally un - supported vessels to expand and produce symptoms. However, beginning at 10 years age, the maturity of the cardiovascular system and the increased systemic pressure causes these single cell lined vessels to expand. As the vessel expands, it creates turbulence and a negative pressure that alters the localized hemodynamics of the blood fl ow to feed blood into the expanded lumen and can recruit new feeder vessels. This process is known as Black-hole phenomenon. The earlier in fetal development, that the loss of growth factors such as PDGF and TGFâl occur, the larger the vascular territory that will be involved. ${ }^{26}$

Hemangiomas pose other perplexing questions that will only be answered as the events that initiate hemangiogenesis are elucidated. For example, the strong gender predilection of hemangioma toward female over male infants (3:1 or more) suggests hormonal effects in hemangiogenesis. I n addition, the anatomical predilection for the head and neck region of juvenile hemangioma must be explained. Perhaps most intriguing from a therapeutic stand point is the spontaneous involution of the lesion. This distinguishing characteristic has been shown to be due in part to apoptosis of the endothelial cells, but the trigger for this process remains unknown. (27)

\section{MANAGE ME NT}

Although most hemangioma proliferates and involute without functional impairment, a significant minority requires some form of intervention. It is important to consider the psychological as well as medical impact of hemangioma, particularly when located on the face. Many central facial lesions leave residual scars or structural deformities, which may have lifelong effects. In the past, treatment options for hemangioma were limited and their potential side effects considerable. Although most hemangioma do not pose significant risks, and careful observation is still the appropriate management option for many lesions, the introduction of relatively safer topical and systemic agents now allows earlier and easier intervention in appropriate cases. ${ }^{28}$ 


\section{MANAGEMENT}

Until recently, intralesional and systemic corticosteroids, which were the mainstay of treatment in cancer chemotherapy, has been proven efficacious for life-threatening hemangioma but also has limited use due to the strong vesicant qualities of the drug, with need for central line access for chronic administration as well as potential peripheral mixed sensory-motor neurotoxicity. ${ }^{29-33}$ In recent years, propranolol therapy has become increasingly more useful in the management of hemangioma that require intervention. LeauteLabreze et al first fortuitously discovered the efficacy of b-blockers for the treatment of hemangioma in $2008 .{ }^{30}$

Theories regarding propranolol's mechanism of action include an initial capillary vasoconstrictive effect,suppression/blockade of growth factors with induction of apoptosis of endothelial cells and blockade of GLUT1 receptors. CD34+ endothelial progenitor cells in hemangioma express factors influencing the renin-angiotensin system. ${ }^{31}$ Because the renin-angiotensin system can stimulate angiogenesis, Itinteang et al suggested that propranol's inhibitory effect on the reninangiotensin system might account for propranolol induced involution. ${ }^{32}$

Angiogenesis inhibitors are theoretically a natural choice for the treatment of hemangiomas.Sirolimus (also known as rapamycin), an inhibitor of mTOR, negatively affects cell proliferation and metabolism as well as angiogenesis. Lasers such flash lamp pulsed dye lasers have also been used. ${ }^{34}$

Occasionally, selective embolization techniques followed by surgical excision is the optimal therapeutic intervention. The goal is to obstruct or reduce the blood flow to the lesion-so that it can be excised with minimal blood loss. For this, various embolization techniques, such as $100 \%$ alcohol, polyvinyl alcohol beads or sodium morhhuate can be used. ${ }^{35}$

\section{SUMMARY AND CONCLUSION}

Recent discoveries have led to an improved understanding of the pathogenesis and clinical behavior of $\mathrm{IH}$. The best scientific evidence to date supports the hypothesis that IHs originate from a subset of endothelial progenitor cells (CD133+) that are stimulated and proliferate under hypoxic conditions. These cells theoretically "hone "to areas of relative hypoxia, such as embryonic fusion planes. $^{36}$

Whatever mechanisms are identified in hemangiogenesis, we have come a long way from the descriptive phase of hemangioma research. The intriguing data of Boye and colleagues suggest one mechanism for hemangioma formation and bring the field a step closer to understanding the molecular etiology of this common tumor. ${ }^{17,} 37$

Newer treatment options for hemangioma may well pose less risk for the patient, allowing the practitioner to intervene in a relatively safe, and more timely manner. Propranolol is now first-line therapy for many practitioners, and it is hoped that future studies will confirm its efficacy and safety. Pulsed dye and other laser modalities may be useful as adjunctive or "mopup"therapy. Other antiangiogenic agents may proveto be more effective in the future. The risk-benefit ratio of any therapy must be scrutinized, keeping in mind that "watchful waiting" may often be appropriate, but timely intervention is sometimes crucial in minimizing long-term sequelae such as functional deformity or permanent scars. ${ }^{38}$

Treatment of vascular anomalies is complex and often involves multiple disciplines and therapeutic options. Referral to a vascular anomalies team is recommended when considering therapy for "problematic"hemangiomas and vascular malformations. Thus, the entire gamut of pathogenesis of hemangioma with a view to enrich its treatment modalities is discussed herewith.

\section{REFERENCES}

1. Mulliken, J and Glowacki, J. 1982. Hemangiomas and vascular malformations in infants and children: a classification based on endothelial characteristics. Plast Reconstr Surg. 69:412-20.

2. AN Haggstrom, BA Drolet, E Baselga et al. "Prospective study of infantilehemangiomas: demographic, prenatal, and perinatal characteristics,". J Pediatrics, 2007; 150(3):2914.

3. Mulliken J and Young AE. 1988. Vascular birthmarks hemangiomas and vascular malformations. W.B. Saunders Co. Philadel phia, Pennsylvania, USA. 24-37.

4. PE North, M Waner, and MC Brodsky. "Are infantile hemangiomas of placental origin?" Ophthalmology 2009; 109(4):633-4.

5. Enjolras O, Mulliken J B, Boon LM, Wassef M, Kozakewich HP, Burrows PE. Noninvoluting congenital hemangioma: a rare cutaneous vascular anomaly. Plast Reconstr Surg 2001;107(7):1647-54. 
6. Frieden IJ. Infantile hemangioma research: looking backward and forward. J Invest Dermatol. 2011;131(12):2345-8.

7. LC Chang, AN Haggstrom, BA Drolet et al. "Growth characteristics of infantile hemangiomas: implications for management," Pediatrics 2008; 122(2):360-7.

8. Mihm MC J r, Nelson J S. Hypothesis: the metastatic niche theory can elucidate infantile hemangioma development. J Cutan Pathol 2010; 37(suppl 1):83-7.

9. YuY, Flint AF, Mulliken J B, Wu J K, Bischoff J Endothelial progenitor cells in infantile hemangioma. Blood 2004; 103(4):1373- 5 .

10. Barnes CM, Huang S, Kaipainen A, et al. Evidence by molecular profiling for a placental origin of infantile hemangioma. Proc Natl Acad Sci U S A 2005;102(52):19097102.

11. J Chang, D Most, S Bresnick et al. "Proliferative hemangiomas: analysis of cytokine gene expression and angiogenesis," Plastic Reconstructive Surg 1999; 103(1):19.

12. Drolet BA, Frieden IJ. Characteristics of infantile hemangiomas as clues to pathogenesis: does hypoxia connect the dots? Arch Dermatol 2010; 146(11):1295-9.

13. North PE, Waner M, Mizeracki A, Mihm MC J r. GLUT1: a newly discovered immunohistochemical marker for juvenile hemangiomas. Hum Pathol 2000;31(1):11-22.

14. Berard, M., et al. 1997. Vascular endothelial growth factor confers a growth advantage in vitro and in vivo to stromal cells cultured from neonatal Hemangiomas. Am J Pathol 150:1315-26.

15. Waner M, North PE, Scherer KA, Frieden IJ, Waner A, Mihm MC J r. The nonrandom distribution of facial hemangiomas. Arch Dermatol 2003; 139(7):869-75.

16. Pittman KM, Losken HW, Kleinman ME, et al. No evidence for maternal-fetal microchimerism in infantile hemangioma: a molecular genetics investigation. J I nvest Dermatol 2006; 126(11):2533-8.

17. Boye $\mathrm{E}$ et al. Clonality and altered behavior of endothelial cell from hemangiomas. J . Clin. Invest 2001; 107:745-52.

18. Takahashi K, Mulliken J B, Kozakewich HP, Rogers RA, Folkman J, Ezekowitz RA. Cellular markers that distinguish the phases of hemangioma during infancy and childhood. J Clin Invest 1994; 93(6):2357-64.

19. Praveen $\mathrm{V}$, Vidavalur $\mathrm{R}$, Rosenkrantz TS, Hussain $\mathrm{N}$. Infantile hemangiomas and retinopathy of prematurity: possible association. Pediatrics 2009; 123(3). Available at: www.pediatrics.org/cgi/content/full/123/3/e484.

20. Mobasheri A, Richardson S, Mobasheri R, Shakibaei M, Hoyland J A. Hypoxia inducible factor-1 and facilitative glucose transporters GLUT1 and GLUT3: putative molecular components of the oxygen and glucose sensing apparatus in articular chondrocytes. Histol Histopathol 2005; 20(4):1327-38

21. J innin M, Medici D, Park L et al. Suppress NFAT-dependent VEGFR1 expression and constitutive VEGFR signaling in infantile hemangioma. Nat Med 2008; 14(11):1236-46.

22. Greenberger S, Boscolo E, Adini I, Mulliken J B, Bischoff J . Corticosteroid suppression of VEGF-A in infantile hemangioma-derived stem cells. N Engl J Med 2010; 362(11): 1005-13.

23. Kleinman ME, Tepper OM, Capla J M, et al. Increased circulating $\mathrm{AC} 133+\mathrm{CD} 34+$ endothelial progenitor cells in children with hemangioma. Lymphat Res Biol 2003; 1(4): 301-7.

24. Ritter MR, Dorrell MI, Edmonds J, Friedlander SF Friedlander M. Insulin-like growth factor 2 and potential regulators of hemangioma growth and involution identified by large-scale expression analysis. Proc $\mathrm{N}$ atl Acad Sci USA 2002; 99(11):7455-60.

25. Peichev $M$, Naiyer $A J$, Pereira $D$, et al. Expression of VEGFR-2 and AC133 by circulating human CD34 (+) cells identifies a population of functional endothelial precursors. Blood 2000; 95(3):952-8.

26. Marx Robert E, Stern D- Oral and Maxillofacial Pathology; A Rationale for Diagnosis and Treatment-Second Edition.

27. Razon MJ, Kraling BM, Mulliken J B and Bischoff J . Increased apoptosis coincides with onset of involution in infantile hemangioma. Microcirculation 1998; 5:189-95.

28. Leonardi-Bee J, Batta K, O'Brien C, Bath- Hextall FJ. Interventions for infantile haemangiomas (strawberry birthmarks) of the skin. Cochrane Database Syst Rev 2011; (5):CD006545

29. Tina S. Chen, Lawrence F. Eichenfield and Sheila Fallon Friedlander. Infantile Hemangiomas: An Update on Pathogenesis and Therapy. Pediatrics 2013.

30. Leaute-Labreze C, Dumas de la Roque E, Hubiche T, Boralevi F, Thambo J B, Taieb A. Propranolol for severe hemangiomas of infancy. N Engl J Med 2008; 358(24):264951.

31. Sans V, dela RoqueED, Berge J, et al. Propranolol for severe infantile hemangiomas: follow-up report. Pediatrics 2009; 124 (3). Available at: www.pediatrics.org/cgi/content/full/ 124/3/e423.

32. Marsciani A, Pericoli R, Alaggio R, Brisigotti M, Vergine G. Massive response of severe infantile hepatic hemangioma to propanolol. Pediatr Blood Cancer 2010; 54(1):176.

33. Ezekowitz RA, Mulliken J B, Folkman J . I nterferon alfa-2a therapy for life- threatening hemangiomas of infancy. $N$ Engl J Med 1992; 326(22):1456-63.

34. Greenberger S, Yuan S, Walsh LA, et al. Rapamycin suppresses self-renewal and vasculogenic potential of stem cells isolated from infantile hemangioma. J I nvest Dermatol 2011; 131(12):2467-76.

35. Ni N, Guo S, Langer P. Current concepts in the management of periocular infantile (capillary) hemangioma. Curr Opin Ophthalmol 2011; 22(5):419-25.

36. Douglas A. Marchuk. Pathogenesis of hemangioma. Department of Genetics, Box 3175, DukeU niversity Medical Center, Durham, North Carolina 27710, USA. Phone: (919) 684-3290; Fax: (919) 681-9193; E-mail: march004@mc.duke.edu.

37. A Visser, T Fitzjohn, and ST Tan. "Surgical management of arteriovenous malformation," J ournal of Plastic, Reconstructive and Aesthetic Surg 2011; 64(3):283-91. 